Journal of Advanced College of Engineering and Management, Vol. 4, 2018

\title{
USE OF ICT IN VITAL EVENT REGISTRATION IN NEPAL AND ITS IMPLEMENTATION CHALLENGES
}

\author{
Sanjeet Paudel ${ }^{1}$, Subarna Shakya ${ }^{2}$ \\ ${ }^{1}$ Senior Software Developer, Department of Civil Registration \\ ${ }^{2}$ Department of Electronics and d Computer Engineering, IOE, Pulchowk Campus, T.U., Nepal \\ Email Address: drss@ioe.edu.np
}

\begin{abstract}
To improve service delivery of government, paper based vital event registration (VER) system should gradually be replaced by ICT based system. This paper highlights the barriers that may stand in implementing ICT in VER. Questionnaire was used to collect primary data. Population size for the research was 6,743 out of which 272 valid responses were used for the research. The gathered data were subjected to demographic study, T-test, ANOVA test and Reliability analysis. The correlation between independent and dependent variables were computed. It was found that nine constructs namely: cost, leadership and management support, organizational process and commitment, usability, human factor, system feature, infrastructure, acts, rules and regulations and political situation are major barriers for implementing ICT based system for vital event registration.
\end{abstract}

Keywords: e-Government, e-Governance, service delivery, ICT Framework, ICT based Vital Event Registration System, Technology Adoption, Barriers to Adoption of ICT

\section{Background}

Information communication and data processing has become inevitable to the success of any organization across the globe. ICT helps in quick processing of data and generating decisions. ICT assists to promote digital government services for businesses and individuals and promote effective operational management [1]. Vital event registration was stared in Nepal since 1950 as record keeping which covered whole country by 1990 as event registration. Department of Civil Registration (DoCR), established in November 2014, is responsible for monitoring vital registration and social security allowance distribution all over Nepal.[5] It has developed MIS for online vital event registration but most of the ward offices still are not able to use the system.

\section{Methodology}

This research included both qualitative and quantitative analysis. To gather data, a structured and closed questionnaire was prepared and distributed to ward offices. The questionnaire included questions regarding demographic study and perceptions. The perception was evaluated using 5 points Likert Scale. 326 responses were obtained in total, out of which only 272 responses were valid and used for the analysis. The data obtained were subjected to analyze using SPSS.

\section{Data Analysis}

To describe the socio-demographic characteristics of respondents, descriptive statistics (frequency, percentage, mean and standard deviation) were used and to find the relationship between independent and dependent variables, Karl Pearson Correlation Coefficient was used. The perception by gender, age and academic qualification were subjected to t-test and ANOVA test. Reliability analysis was carried out to find the internal consistency of the variables. 


\section{4. $\quad$ Findings}

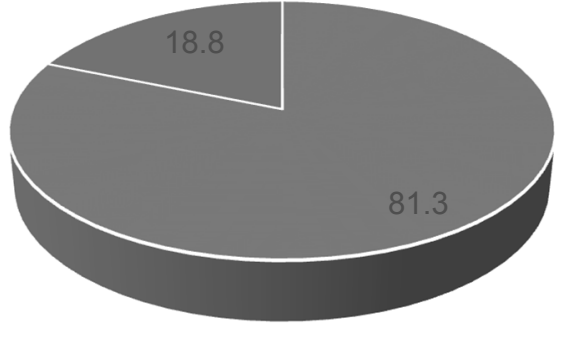

- Male . Female

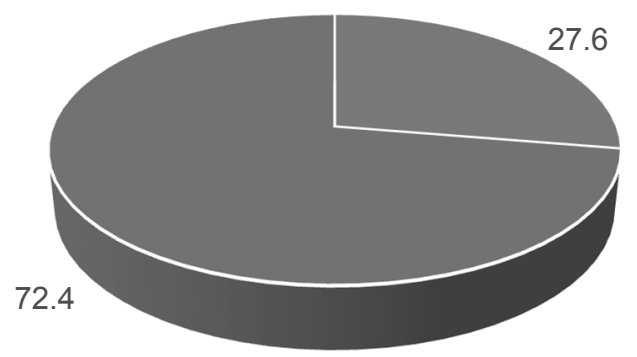

- Online Software - Manual/Paper Based

The responses were collected from 37 districts. Out of the total respondents, $81.3 \%$ of respondents were male while $18.8 \%$ of respondents were female. By analyzing the age group of respondents, it was found that most of the respondents were aged between 25 to 34 years. $56.3 \%$ of respondents fell into this group while only $11 \%$ respondents in this study were 18-24 years old. Further, academic qualifications of the respondents were studied. More than $50 \%$ of the respondents were educated to Bachelor's level while $9.2 \%$ of them had passed SLC only.

\section{Method of vital event registration}

Currently, about $28 \%$ of total respondents are using online software for vital event registration while about $72 \%$ of them are still using the same traditional paper-based method. No any ward offices use the offline system for vital event registration. In this digitalized world, this is not the satisfactory usage of online system.

Table 1: Activities on vital event registration

\section{Involvement of respondents in VE activities}

\begin{tabular}{|c|l|c|}
\hline S.N. & \multicolumn{1}{|c|}{ Activities } & Use of online system (\%) \\
\hline 1 & $\begin{array}{l}\text { For filling application form by } \\
\text { public }\end{array}$ & 92.85714 \\
\hline 2 & For event registration & 97.14286 \\
\hline 3 & For certificate generation & 97.22222 \\
\hline 4 & $\begin{array}{l}\text { For issuing duplicate copy of } \\
\text { certificates }\end{array}$ & 94.3662 \\
\hline 5 & For reporting to upper level & 84.61538 \\
\hline 6 & For scanning documents of public & 36.92308 \\
\hline
\end{tabular}

Table 1 shows that most of the activities regarding vital event registration are mostly done by using online software. This includes event registration, certificate generation and issuing duplicate copy of certificates. There are still some offices which are not involved in using online software for filling application form by public and reporting. Public awareness programs should be run on timely basis and effective reporting mechanism should be developed. The above data shows most of the ward offices do not scan documents of public.

\section{Advantages of Using ICT in Vital Event Registration}

Out of 272 responses, three responses did not include the answers to the questions regarding the advantages. Respondents are found positive towards the fact that with the use of ICT in vital event registration, time required to serve a service seeker decreases $(80.5 \%$ responses), quality of service 
increases (93.8\% responses), capacity of government increases (89.3\% responses) and complexity of work decreases ( $83.1 \%$ responses). Number of service seekers per day is not so affected by using ICT.

\section{ICT Status of respondents' office}

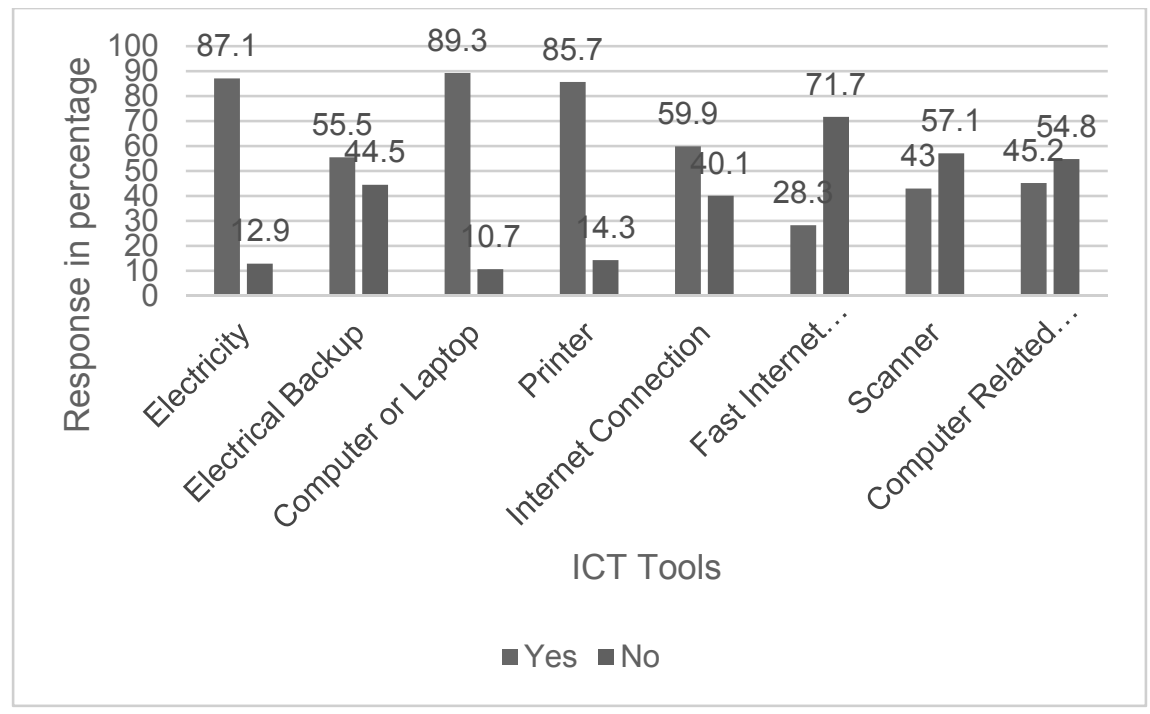

Fig1: ICT status of ward offices

The figure 1 shows the ICT status of respondents' offices. $87.1 \%$ of the offices have facilities of electricity but only $55.5 \%$ of them have the backup facility. Most of these offices have computer or laptop (89.3\%). About half of the offices have access to the internet, but the speed of the internet is relatively slow. Only $28.3 \%$ of the offices have connection to fast internet. More than $85 \%$ of the offices are provided with printers but more than $57 \%$ do not have scanners. The study shows that more than $50 \%$ of the offices lack manpower who can use computers. Government should take the steps so that each office can be equipped well and at least one employee with basic knowledge on computer should be provided to the office.

\section{Correlation Matrix}

To find the relationship between dependent and independent variables, Karl Pearson Correlation Coefficient was computed using SPSS. The nature of relationship to the Use of System from all other variables are shown in the table 2 .

Table 2: Relationship of variables to use of system

\begin{tabular}{|l|c|l|}
\hline \multicolumn{1}{|c|}{ Variables } & r value & \multicolumn{1}{|c|}{ Relation } \\
\hline Cost & .393 & Moderate positive relationship \\
\hline $\begin{array}{l}\text { Leadership and Management } \\
\text { Support }\end{array}$ & .435 & Strong positive relationship \\
\hline $\begin{array}{l}\text { Organizational Process and } \\
\text { Commitment }\end{array}$ & .492 & Strong positive relationship \\
\hline Usability & .456 & Strong positive relationship \\
\hline Human Factor & .405 & Strong positive relationship \\
\hline System Feature & .430 & Strong positive relationship \\
\hline Infrastructure & .414 & Strong positive relationship \\
\hline Acts, Rules and Regulations & .438 & Strong positive relationship \\
\hline Political Situation & .278 & Weak positive relationship \\
\hline
\end{tabular}




\section{Reliability Analysis}

Cronbach's Alpha was used to determine if the Likert scale used in this research. The value of Cronbach's Alpha was obtained to be 0.915 which is very near to 1 . This indicates a high level of internal consistency for our scale.

\section{Challenges of Implementation of ICT in Vital Event Registration}

With the computed correlation coefficients, it was found that to implement ICT based vital event registration system, following constructs act as challenges:

- $\quad$ Cost

- $\quad$ Leadership and Management Support

- $\quad$ Organizational Process and Commitment

- Usability

- Human Factor

- $\quad$ System Feature

- Infrastructure

- $\quad$ Acts, Rules and Regulations and

- Political Situation

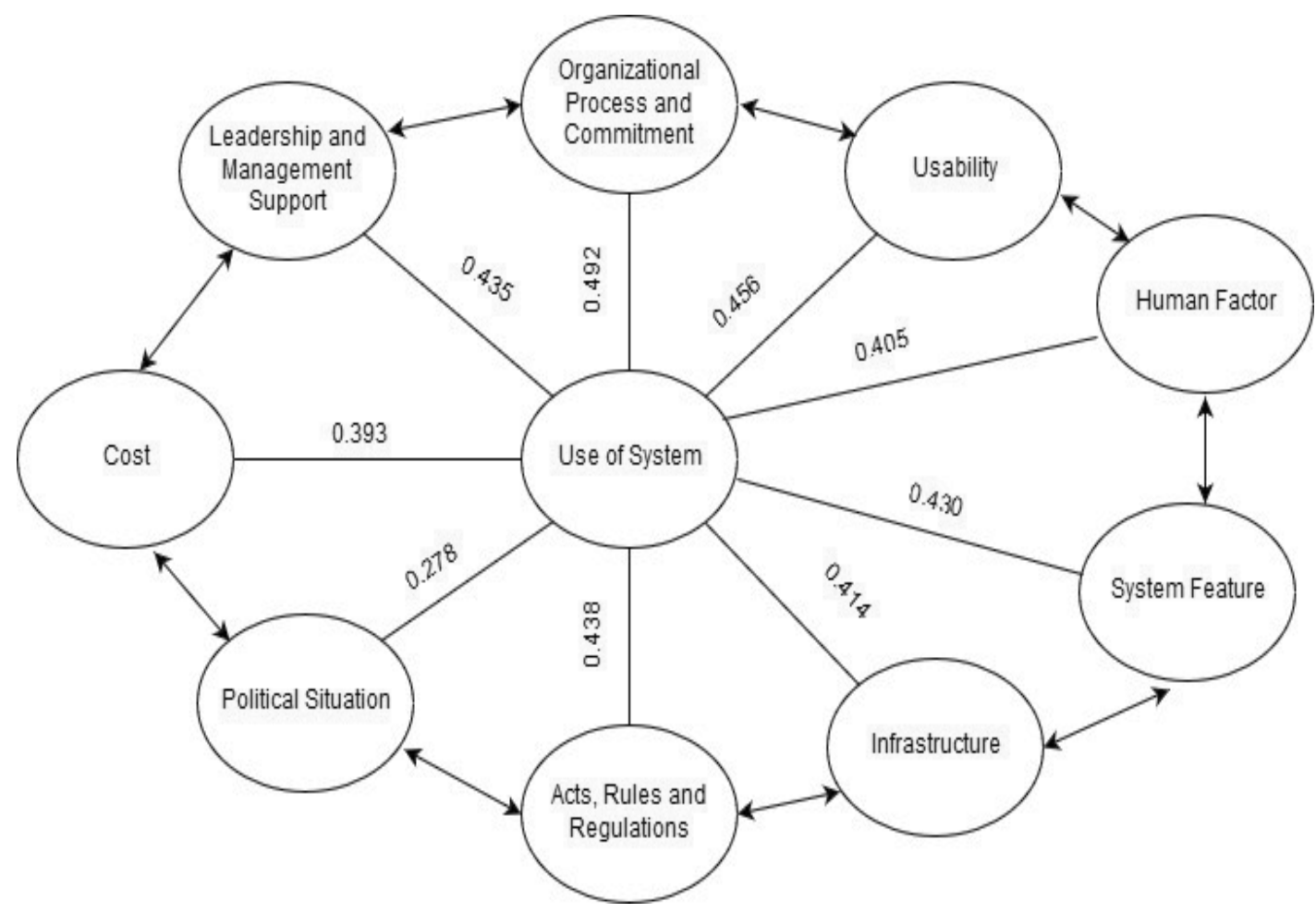

Fig. 2: Challenges in implementing ICT in VER

\section{ICT Framework for Vital Event Registration in Nepal}

The study has identified that ICT enabled VER system require effective leadership and management support, improved organizational process and commitment, human factor, quality system feature, adequate infrastructure and effective acts, rules and regulation. Based on this, ICT framework has been designed which is shown in figure 3 . 


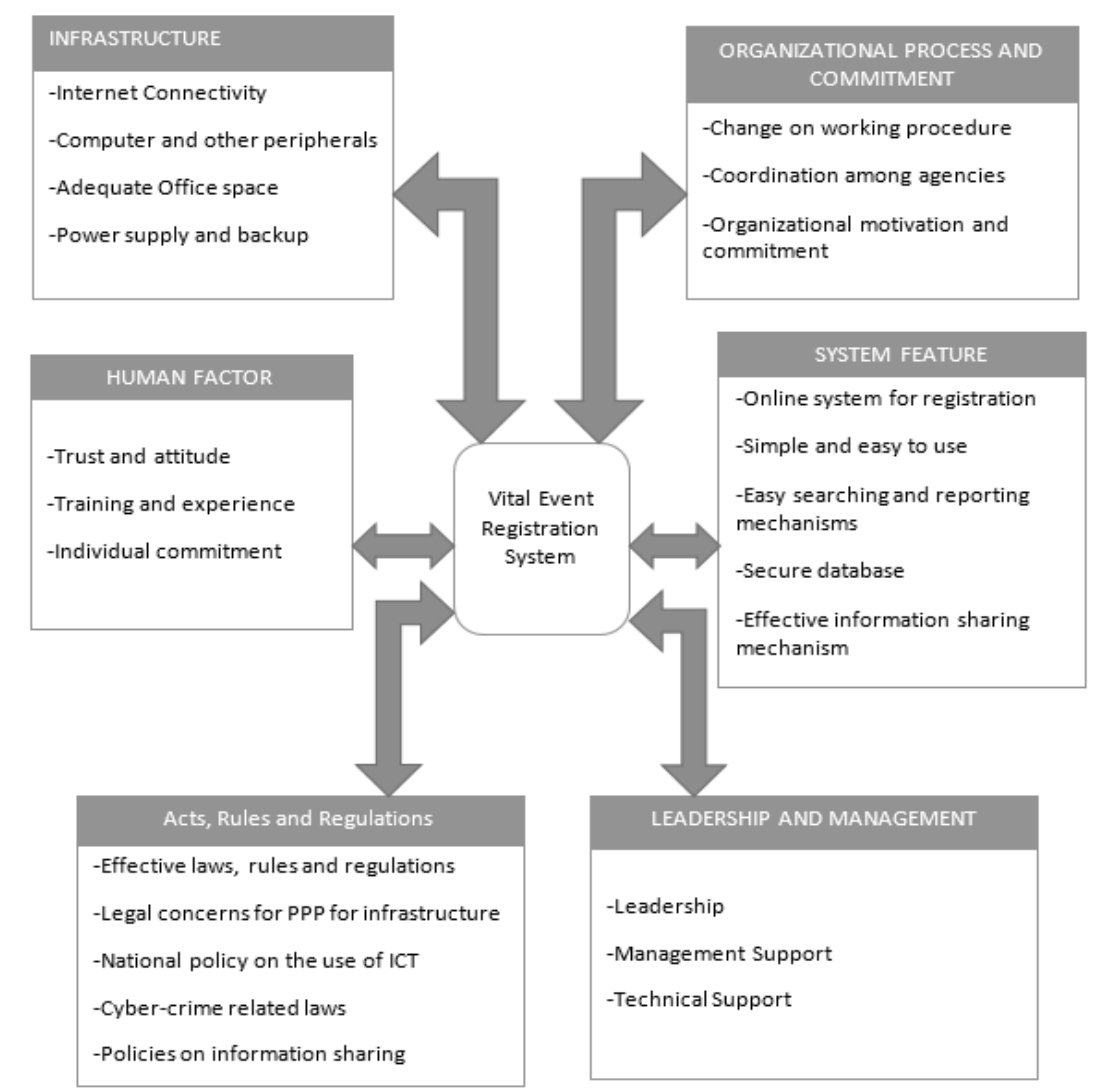

Fig.3: ICT Framework for vital event registration

\section{Proposed System Architecture of ICT Enabled VER System}

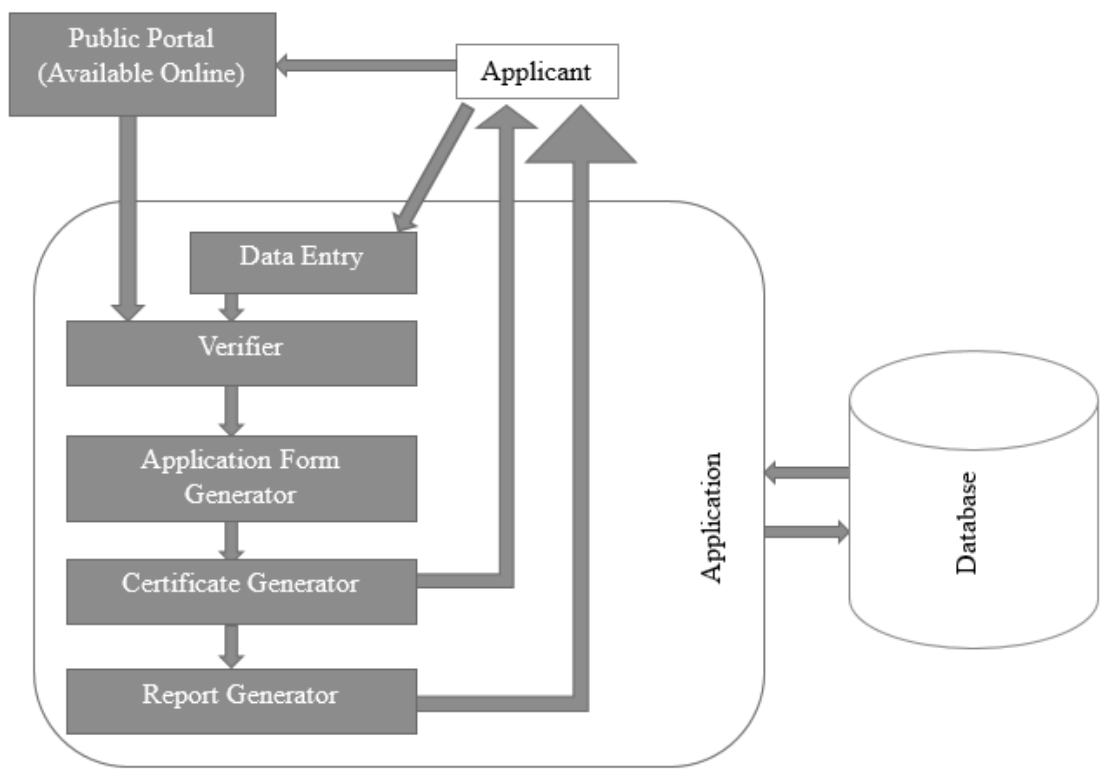

Fig.4: Proposed System Architecture of ICT based VER system

Public portal is online tool through which public can provide their information. Application consists data entry section, verification section, form generator, certificate and report generator. It consists of centralized database containing data, procedures, packages, triggers, partitions, etc. and security protocols applied to it. 


\section{Conclusions}

Vital events are so much necessary that if not registered, people can be deprived of benefits that $\mathrm{s} / \mathrm{he}$ can earn. Every events should be properly registered for the certainty of individual rights and for maintain accurate statistics by the government. This can help government in formulating effective plans and policies. Most of the countries around the world are currently adopting software for vital event registration. This is in fact necessary because paper based system degrades the government service quality in a way that the papers can be lost or torn down due to which records cannot always be obtained whenever and wherever necessary.

The researcher has studied the use of ICT in vital event registration in Nepal and the implementation challenges. A classical approach of questionnaire was prepared to collect data. 272 valid response were collected for the research. With the collected data, researcher found out the existing method of registration, infrastructural status on the ward offices and the challenges ward offices are facing for implementing ICT. While going through the data, it is found that most of the ward offices intend to use information and communications technology but they are facing some difficulties like low cost, inadequate infrastructures, weak leadership and management support, weak organization process and commitment, less skilled manpower and other human factors, difficulties in system, harsh political situation and ineffective laws, rules and regulations. The correlation coefficient between these variables to the use of system are identified and their relationship level has been defined.

Furthermore, researcher has designed an ICT framework for vital event registration. The framework includes infrastructure, organizational process and commitment, human factor, system feature, leadership and management and acts, rules and regulation as major constructs for ICT based vital event registration system. Based on this, researcher has proposed a system for ICT based vital event registration and depicted the block diagram of the same.

Thus, online vital event registration is more secured, less time consuming and more reliable as compared to traditional paper based system. Such system speeds up the service delivery, makes service more effective and promotes nation towards automation and eventually towards e-readiness. Hence, such system should be developed and flourished.

\section{Recommendations}

Through the research analysis, researcher has made the following recommendations for introducing information and communication technology for vital event registration in Nepal and make the process sustainable:

- Government should make proper budgeting plans for local levels so that local level offices need not to stay untouched with internet connectivity. Wireless connectivity should be provided to those areas where wired connectivity cannot be reached.

- $\quad$ Each individual office should be provided with computers or laptops, printers, scanners, etc. for doing regular official activities.

- $\quad$ Training and capacity building classes should be provided to staffs of local levels.

- Leaders and management level staffs should be self-motivated towards using ICT and should also motivate their juniors.

- $\quad$ Strict laws, rules and regulations should be formulated and implemented effectively.

- $\quad$ Reward and punishment policy should be developed.

- Inter-agency linkage should be developed for effective and efficient service delivery.

- $\quad$ Centralized system should be developed so that transparency shall be maintained.

- $\quad$ Strong servers with regular backup provisions should be set up at the central level. 


\section{References}

1. "Department of Civil Registration," [Online]. Available: www.docr.gov.np. [Accessed 1610 2017].

2. "Global Civil Registration and Vital Statistics," 1405 2014. [Online]. Available: http://www.worldbank.org/content/dam/Worldbank/document/HDN/Health/CRVSScalingupoverview 5-28-14 web.pdf. [Accessed 0801 2018].

3. "ICT and e-government," 0801 2018. [Online]. Available: https://www.government.nl/topics/public-administration/central-public-administration/ict.

4. Bhattarai A. K., "Third Regional Workshop on Production and Use of Vital Statistics," 2014.

5. Gautam B. R., "Civil Registration and Vital Statistics," Policy and Practices in Nepal, p. 3, 2016.

6. "Birth, Death and other Personal Events Registration Act", 1976.

7. Chang L., "Coss-Cultural Differences in International Management using KluckhohnStrodtbeck framework," Journal of American Academy of Business, vol. 2, no. 1, 2002.

8. Flak L., Olsen D. and Wolcott P., "Local E-Government in Norway," Scandinavian Journal of Information Systems, vol. 17, no. 2, pp. 41-48, 2005.

9. "Leard Statistics, "Cronbach's Alpha in SPSS Statistics," [Online]. Available: https://statistics.laerd.com/spss-tutorials/cronbachs-alpha-using-spss-statistics.php.

[Accessed 0705 2018].

10. Alshehri M. and Drew S., "E-Government Fundamentals," in Proceedings of the IADIS International Conference ICT, Society and Human Beings 2010, 2010.

11. M. Department of Civil Registration, "Annual Report of Vital Event Registration, 2072".

12. Ajayi, O. V. "Distinguish between primary sources of data and secondary sources of data," Makurdi, 2017.

13. OECD, "OECD E-Government Flagship Report: The E-Government Imperative," Public Management Committee, OECD, Paris, 2003.

14. Lai P., "The Literature Review of Technology Adoption Models and Theories for the Novelty Technology," JISTEM- Journal of Information Systems and Technology Management, vol. 14, no. 1, 2017.

15. QuestionPro, "LIkert Scale Questions, Survey and Examples," [Online]. Available: https://www.questionpro.com/article/likert-scale-survey-questions.html. [Accessed 0115 2018].

16. Statics How to, "Correlation Coefficient: SimpleDefinition, Formula, Easy Calculation Steps," [Online]. Available: http://www.statisticshowto.com/probability-andstatistics/correlation-coefficient-formula/. [Accessed 0705 2018].

17. StatPac Inc., "Survey Sampling Methods," [Online]. Available: https://www.statpac.com/surveys/sampling.htm. [Accessed 2804 2018].

18. TechSansar, "TechSansar," [Online]. Available: https://techsansar.com/nepali-it/practicalegovernment-scenario-nepal/. [Accessed 17 April 2018].

19. The Economic Times, "Definition of 'Random Sampling'," [Online]. Available: https://economictimes.indiatimes.com/definition/random-sampling. [Accessed 2804 2018].

20. United Nations, "United Nations e-Government Survey: From e-Government to Connected Governance," United Nations, New York, 2008.

21. Ebrahim Z. and Irani Z., "E-government adoption: architecture and barriers," 2005. 